\title{
Synthesis and Characterization of Green Biodegradable Palm Oleic Acid Based Polyester
}

\author{
Murad Bahadi 1,2(D), Nadia Salih 2,* (D), Jumat Salimon 2(D) \\ 1 Faculty of Education, Hadhramout University, Hadhramout, Yemen; muradbahadi@yahoo.com (M.B.); \\ 2 Department of Chemical Sciences, Faculty of Science and Technology, Universiti Kebangsaan Malaysia, 43600 UKM \\ Bangi, Selangor, Malaysia; nadiaalnami@ hotmail.com (N.S.); jumatsal@ gmail.com (J.S.); \\ * Correspondence: nadiaalnami@ hotmail.com (N.S.);
}

Scopus Author ID 24072094400

Received: 1.02.2021; Revised: 2.03.2021; Accepted: 5.03.2021; Published: 10.03.2021

\begin{abstract}
The palm oleic acid-based polyester was prepared from epoxidized oleic acid (EOA) as a monomer through the polycondensation polymerization at $120{ }^{\circ} \mathrm{C}$ with different polymerization times $(6,12,18,24$, and $30 \mathrm{hr})$, respectively. The synthesized palm oleic acid-based polyester (POABP) showed about $97 \%$ yield. The FTIR spectrum showed the peaks of $\mathrm{C}=\mathrm{O}$ and $\mathrm{C}-\mathrm{O}$ of the ester carbonyl group appeared at $1735 \mathrm{~cm}^{-1}$ and $1244 \mathrm{~cm}^{-1}$, respectively. The ${ }^{1} \mathrm{H}$ NMR showed the proton ester group -COO-CH- appeared at $4.7 \mathrm{ppm}$, while the ${ }^{13} \mathrm{C}$ NMR showed $\mathrm{C}=\mathrm{O}$ ester appeared at $173.79 \mathrm{ppm}$, respectively. The polyester molecular weights were between $1963 \mathrm{~g} / \mathrm{mol}$ to $5501 \mathrm{~g} / \mathrm{mol}$ and having a glass transition temperature of $-19^{\circ} \mathrm{C}$. The thermal degradations of the polyester occurred at temperatures higher than $328^{\circ} \mathrm{C}$. The synthesized palm oleic acid-based polyester may be used as a precursor in the plastic industry.
\end{abstract}

Keywords: plant oils; epoxidized oleic acid; palm oleic acid based polyester; polymerization.

(C) 2021 by the authors. This article is an open-access article distributed under the terms and conditions of the Creative Commons Attribution (CC BY) license (https://creativecommons.org/licenses/by/4.0/).

\section{Introduction}

Oleic acid is known as an omega-nine fatty acid and it is a prime example of a monounsaturated fatty acid (MUFA). Oleic acid (OA) or cis-9-octadecenoic acid is the most widely distributed natural fatty acid and present in most liquid vegetable oils. It is the major component of fatty acid in olive oil obtained from olive's ripe fruit (Olea europaea). OA makes up 55-80\% of olive oil, 15-20\% of grapeseed oil, and sea buckthorn oil [1]. Other common vegetable oils such as corn oil, soybean oil and palm oil contain OA in the range of $10-40 \%$. Olive oil contains $75 \%$ OA, which is more than 5 times higher than safflower oil. OA is best obtained from plants or vegetable oils and useful raw material in the modification and the production of healthier edible vegetable oil. It is a healthier source of oils and fats in the diet and is commonly used to replace animal fat sources high in saturated fat [2].

Nowadays, nearly $80 \%$ of all polymeric materials produced in the petrochemical industry are derived from fossil fuel (non-renewable) resources. Unfortunately, plastics' growing demand has created a burden on the environment regarding unremitting exploitation and generation of enormous wastes and by-products from polymers and plastics production. Hence, the production of biopolymers has garnered research interest to provide a solution to this problem. Triacylglycerol oils and fatty acids are the key sources for biopolymers. Oilbased biopolymers have numerous benefits over petroleum-based polymer monomers. They 
are biodegradable by microorganisms that release non-toxic compounds in the environment and are relatively cheaper than petroleum polymers [3].

Plant oils are one of the very perspective, accessible and cheap types of renewable sources, which, together with biodegradability and low toxicity, made them an attractive raw material for the chemical industry. Common plant oils are mixtures of triacylglycerols, which are composed of three fatty acid moieties connected by a glycerol backbone. These fatty acids, either saturated or unsaturated, normally have 14 to 22 carbon atoms in each hydrocarbon chain, resulting in a relatively high overall carbon content. More importantly, the fatty acids in plant oils are mostly unsaturated with 0 to 3 double bonds per carbon chain. These fatty triacylglycerols are essential for having active reaction sites from the double bonds of the fatty acids and the allylic position and the ester groups present in the triacylglycerols. The molecular structure and nature of the triglycerols allow the incorporation of more reactive functional groups such as hydroxyl, epoxy, or carboxyl groups. The four major classes of polymers that are plant-oils-based are polyurethane, polyester, polyether, and polyolefin [4-6].

Plant oils that are liquid at room temperature are extracted by pressing or solvent extraction. There are many types of plant oil produced worldwide, and palm oil is one of them. Palm oil consists of unsaturated fatty acids such as OA, linoleic acid, and linolenic acid with one, two, or three carbon-carbon bonds. OA has the highest percentage in palm oil. Hence OA is applicable for any further research for reaction and chemical modification. Among the chemical modifications of OA, epoxidation is an easy and effective method to produce intermediate products that can be used in various applications. The epoxidation process is one of the newest methods where fatty acids are converted to a three-member epoxide ring that is oxirane ring when the double bond of carbons reacts with active oxygen [7].

Various compounds such as alcohols, glycols, carbonyl compounds, olefinic compounds, alkanolamines, and polymers can be synthesized from epoxidized oil as starting materials. Epoxidized oil has been widely used as a polymer stabilizer and plasticizer in polyvinylchloride (PVC). Epoxidized oils are suitable as an intermediate for various end products manufacture that can be useful for industrial purposes. This is because most organic synthesis requires high reactivity of oxirane rings of epoxidized oil to make them involved Hence, palm oil's economic value is increasing because of the conversion of palm oil into epoxidized palm oil an important starting material for synthesized end products such as polyesters. Polyesters comprise a range of materials with different chemical structures and mechanical properties. Polyesters are extensively applied in laminates, industrial construction and installation, molding compounds, coatings, plastic, and adhesives. There are several methods of synthesizing polyesters, such as polycondensation of hydroxyl acids, diacid, and a diol, or by ring-opening polymerization of lactones [8]. This work aims to synthesize and characterize $\mathrm{POABP}$ from EOA as a monomer using Malaysian high-free fatty acid crude palm oil (HFFA-CPO) as an OA source.

\section{Materials and Methods}

\subsection{Materials.}

Malaysian HFFA-CPO was obtained from a local refinery, Sime Darby, Sdn. Bhd, Carey Island, Selangor. The entire chemicals and solvents used in this study include hydrogen peroxide 30\%, formic acid $85.5 \%$, ethyl acetate, anhydrous sodium sulfate $99 \%$, and tetrahydrofuran $99.5 \%$ were analytical reagents and were used without additional purification. 


\subsection{Instrumentation.}

Calorimetric measurements of POABP were conducted using a differential scanning calorimetry (DSC) thermal analysis system in the range of -50 to $500^{\circ} \mathrm{C}$ at a heating rate of 20 ${ }^{\circ} \mathrm{C} / \mathrm{min}$. The glass transition temperature $\left(\mathrm{T}_{\mathrm{g}}\right)$ and decomposition temperature $\left(\mathrm{T}_{\mathrm{d}}\right)$ were determined from the DSC thermogram of the second scan. The nuclear magnetic resonance analysis (NMR) for proton ${ }^{1} \mathrm{H}$ and ${ }^{13} \mathrm{C}$ (NMR) was carried out according to Gunstone et al. (2007) [9]. The spectra were recorded on a Bruker AV400111 (USA) $400 \mathrm{MHz}$ at $30^{\circ} \mathrm{C}$. Tetramethylsilane (TMS) was used as an internal chemical shift reference, and deuterated chloroform $\left(\mathrm{CDCl}_{3}\right)$ was used as a solvent in all experiments. Fourier transforms infrared spectroscopy (FTIR) was carried out according to Sherazi et al. (2009) [10]. FTIR spectra of the products were recorded (Perkin Elmer Spectrum GX spectrophotometer) in the range of $400-4000 \mathrm{~cm}^{-1}$. The molecular weight (MW) of the POABP was determined at $35^{\circ} \mathrm{C}$ using a gel permeation chromatography (Agilent 1200 GPC) system equipped with a refractive index detector and SHODEX K-802 and K-806M columns. The weight-average molecular weight $\left(\mathrm{M}_{\mathrm{w}}\right)$, number-average molecular weight $\left(\mathrm{M}_{\mathrm{n}}\right)$, and polydispersity index $\left(\mathrm{M}_{\mathrm{w}} / \mathrm{M}_{\mathrm{n}}\right)$ were determined from the elution curves obtained from this method. Calorimetric measurements (DSC) of the POABP were conducted using a differential scanning calorimetry (DSC) thermal analysis system in the range of -50 to $500^{\circ} \mathrm{C}$ at a heating rate of $20^{\circ} \mathrm{C} / \mathrm{min}$. The glass transition temperature $\left(\mathrm{T}_{\mathrm{g}}\right)$ and decomposition temperature $\left(\mathrm{T}_{\mathrm{d}}\right)$ were determined from the second scan's DSC thermogram.

\subsection{Synthesis of EOA.}

OA was first separated from high free fatty acids crude palm oil using a lowtemperature methanol crystallization method based on the study of Bahadi et al. (2019) [11]. The isolated OA was then reacted with hydrogen peroxide and formic acid via a process referred to as epoxidation to generate EOA. The temperature reaction has been slowly rising from 60 to $80^{\circ} \mathrm{C}$ to complete the reaction with $350 \mathrm{rpm}$ of agitation speed for $2 \mathrm{hr}$. The molar ratio of hydrogen peroxide: formic acid: oleic acid was 20:2:1, respectively [12]. After $2 \mathrm{hr}$, the organic layer (containing the epoxide) was separated and mixed with ethyl acetate. The solution was rinsed three times with water to eliminate residual $\mathrm{H}_{2} \mathrm{O}_{2}$. The water content was removed with anhydrous sodium sulfate, while the ethyl acetate was evaporated in a vacuum rotary evaporator at $45^{\circ} \mathrm{C}$. The resulting precipitate was obtained and recrystallized from ethanol to produce EOA as a whitish powdery solid. The iodine value (IV) and oxygen oxirane content (OOC) were calculated according to the AOCS (Cd 1-25) and (Cd 9-57) standard methods [13], respectively, using the following formula:

- Iodine value:

$$
\mathrm{I} . \mathrm{V}=\frac{12.69 \times \mathrm{N}\left(\mathrm{V}_{\mathrm{b}}-\mathrm{V}_{\mathrm{s}}\right)}{\mathrm{W}}
$$

where,

$\mathrm{N}=$ Normality of the $\mathrm{Na}_{2} \mathrm{~S}_{2} \mathrm{O}_{3}$ solution used.

$\mathrm{V} b=$ Volume $(\mathrm{ml})$ of $\mathrm{Na}_{2} \mathrm{~S}_{2} \mathrm{O}_{3}$ solution used for the blank test.

$\mathrm{V}_{\mathrm{s}}=$ Volume $(\mathrm{ml})$ of $\mathrm{Na}_{2} \mathrm{~S}_{2} \mathrm{O}_{3}$ solution used to determine the sample.

$\mathrm{W}=$ Weight $(\mathrm{g})$ of the sample test portion.

12.69 is used to transfer equivalent thiosulphate to $\mathrm{g}\left(\mathrm{I}_{2}\right)$. The molecular mass unit or relative molecular unit of $\mathrm{I}_{2}$ is 126.9 . 
- Relative percentage conversion to oxirane (RCO \%):

$$
\mathrm{RCO}=\frac{\text { oOCexp }}{\text { oOCthe }}
$$

where,

$\mathrm{OOC}_{\exp }=$ Experimental oxygen oxirane

$\mathrm{OOC}_{\text {the }}=$ Theoretical maximum oxirane oxygen from the expression:

where:

$$
\text { ooCexp }=\frac{\mathrm{V} \times \mathrm{N} \times 1.60}{W t}
$$

$\mathrm{V}=$ Volume $(\mathrm{mL})$ of the $\mathrm{HBr}$ solution

$\mathrm{N}=$ Normality of the $\mathrm{HBr}$.

$\mathrm{W}=$ Weight $(\mathrm{g})$ of the sample.

where,

$$
\text { ooCthe }=\frac{\mathrm{I} V_{o} / 2 A_{i}}{100+\left(I V_{o} / 2 A_{i}\right) A_{o}} A_{o} \times 100
$$

$A_{i}$ (126.9) and $A_{o}(16.0)$ are the atomic weights of iodine and oxygen, respectively.

$I V_{o}=$ Initial iodine value of the sample.

\subsection{Synthesis of POABP.}

POABP was prepared by heating the epoxide monomer at $120^{\circ} \mathrm{C}$ for $6,12,18,24$, and $30 \mathrm{hr}$ with magnetic stirring at $300 \mathrm{rpm}$. The polymer product was then cooled to room temperature.

\section{Results and Discussion}

\subsection{Synthesis of EOA.}

Epoxidized oils, which are produced through the epoxidation of renewable materials, such as plant oils and their unsaturated fatty plant oils, have recently garnered interest in resolving environmental and economic issues. Furthermore, epoxidation of unsaturated fatty acids such as OA $\left(\mathrm{C}_{18: 1}\right)$ has advantages for industrial applications such as plasticizers and plastic stabilizers. EOA has been employed to manufacture adhesives, polymers, lubricants, and plastics such as polyesters $[14,15]$. There are several methods to epoxidize the double bonds of unsaturated fatty acids, such as epoxidation by the conventional method, epoxidation using acid ion exchange, epoxidation using enzymes, and epoxidation using metal catalysts [16-18]. In this study, a peracid from a short or long-chain fatty acid such as formic acid or acetic acid act as an oxygen carrier and concentrated hydrogen peroxide $\left(\mathrm{H}_{2} \mathrm{O}_{2}\right)$ acts as an oxygen carrier, and concentrated hydrogen peroxide $\left(\mathrm{H}_{2} \mathrm{O}_{2}\right)$ acts as an oxygen donor used for epoxidation of OA. Formic acid is preferred to acetic acid as an oxygen carrier because, owing to its high reactivity, no catalyst is required to form performic acid.

OA's epoxidation reaction was carried out at $80^{\circ} \mathrm{C}$ with a low agitation speed of 350 rpm for $2 \mathrm{hr}$. The molar ratio of hydrogen peroxide, formic acid, and OA was 20:2:1. Table 1 shows that the yield of epoxidized oleic acid was $85.3 \%$, while the relative percentage conversion to oxirane ( $\mathrm{RCO} \%$ ) was $97.40 \%$. The calculated iodine value showed a significant decrease from 91.88 for OA to 2.284 for EOA. The final EOA product was a white powderysolid material, as shown in Figure 1. This is consistent with the study by Kozhevnikov et al. (1998) [19], who also suggested an optimum reaction temperature range of $60-80^{\circ} \mathrm{C}$ for OA's 
epoxidation. The results indicated that a moderate epoxidation condition supports the formation of oxirane ring from OA. Abdullah and Salimon (2010) [20] also noted that epoxidation reaction carried out at higher temperature resulted in an unwanted increase in the degree of oxirane ring cleavage to glycol and hence reduced the yield. The stirring speed of $350 \mathrm{rpm}$ was also found to be adequate to overcome mass transfer resistance under the studied temperature range, as suggested by earlier studies [21, 22].

Table 1. Physicochemical properties of EOA.

\begin{tabular}{l|l} 
Parameter & Values \\
\hline Yield \% of EOA & 85.3 \\
\hline OOC $_{\text {theo }}$ of EOA & 5.4751 \\
\hline OOC $_{\text {exp } \text { of EOA }}$ & 5.333 \\
\hline RCO $\%$ & 97.40 \\
\hline IV of EOA & 2.284 \\
\hline IV of OA & 91.88 \\
\hline
\end{tabular}

Notes: OOC $_{\text {theo }}=$ Theoretical oxirane oxygen content, $\mathrm{OOC}_{\exp }=$ Experimental oxirane oxygen content, RCO $\%=$ Relative percentage conversion to oxirane, IV = Iodine value

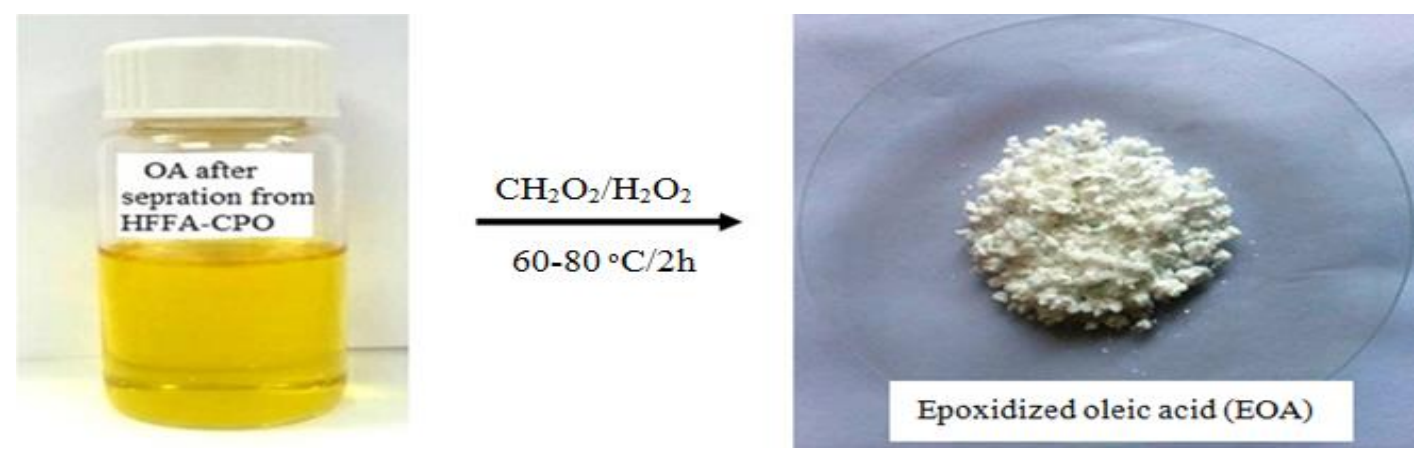

Figure 1. The final epoxidized oleic acid product.

3.2. Characterization analysis of $O A$ and $E O A$.

\subsubsection{FTIR analysis.}

FTIR was used to verify the presence of the oxirane ring of EOA. The FTIR spectra were used to comparatively analyze OA and EOA, as shown in Figure 2. The oxirane ring signal can be detected at $845 \mathrm{~cm}^{-1}$, while carboxylic acid carbonyl functional groups $(\mathrm{C}=\mathrm{O})$ absorption bands of OA and EOA are denoted by peaks at 1708 and $1703 \mathrm{~cm}^{-1}$, respectively, while the stretching vibration peak of $\mathrm{C}=\mathrm{C}$ for $\mathrm{OA}$ can be detected at $3008 \mathrm{~cm}^{-1}$. The peaks at $2927-2856 \mathrm{~cm}^{-1}$ indicate the $-\mathrm{CH}_{2}-$ and $-\mathrm{CH}_{3}$ scissoring of OA and EOA, while the absorption bands at $726 \mathrm{~cm}^{-1}$ indicate $\mathrm{C}-\mathrm{H}$ vibration.

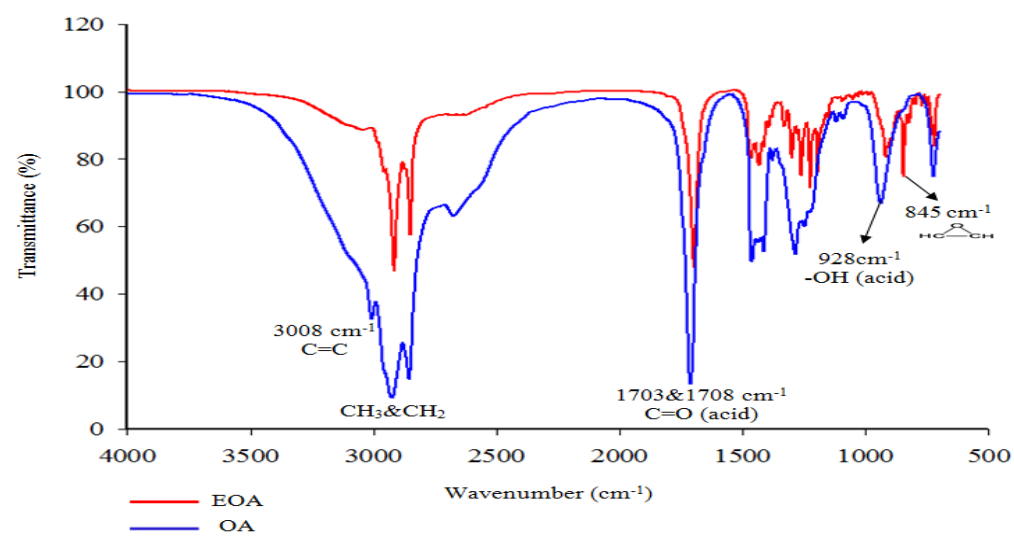

Figure 2. The FTIR spectrum of OA and EOA. 


\subsubsection{NMR analysis.}

Typical ${ }^{1} \mathrm{H}$ NMR signals of OA and EOA appear in the region between 0.8 and 5.36 ppm, as shown in Figures 3 and 4, respectively. The ${ }^{1} \mathrm{H}$ NMR spectrum for the EOA shows a characteristic signal for the (-CH-O-CH-) group at $2.93 \mathrm{ppm}$. The signals at $0.9 \mathrm{ppm}$ indicate terminal methyl group $\left(-\mathrm{CH}_{3}\right)$ of $\mathrm{OA}$, which also appears in EOA at 0.87- 0.88 ppm. However, the methylene proton signal $(-\mathrm{CH}=\mathrm{CH}-)$ was shifted at $5.36 \mathrm{ppm}$ of $\mathrm{OA}$ while they disappeared in EOA. The methylene groups were adjacent to one double bond $\left(-\mathrm{CH}_{2}-\mathrm{C}=\mathrm{C}-\right)$ at $2.03 \mathrm{ppm}$ of $\mathrm{OA}$, while they also disappeared in EOA. The signal at $2.36 \mathrm{ppm}$ of OA attribute to the $-\mathrm{CH}_{2}-$ $\mathrm{COOH}$ group, which also appears in EOA at 2.33-2.37 ppm. The signal at $7.28 \mathrm{ppm}$ referred to $\mathrm{CDCl}_{3}$ solvent.
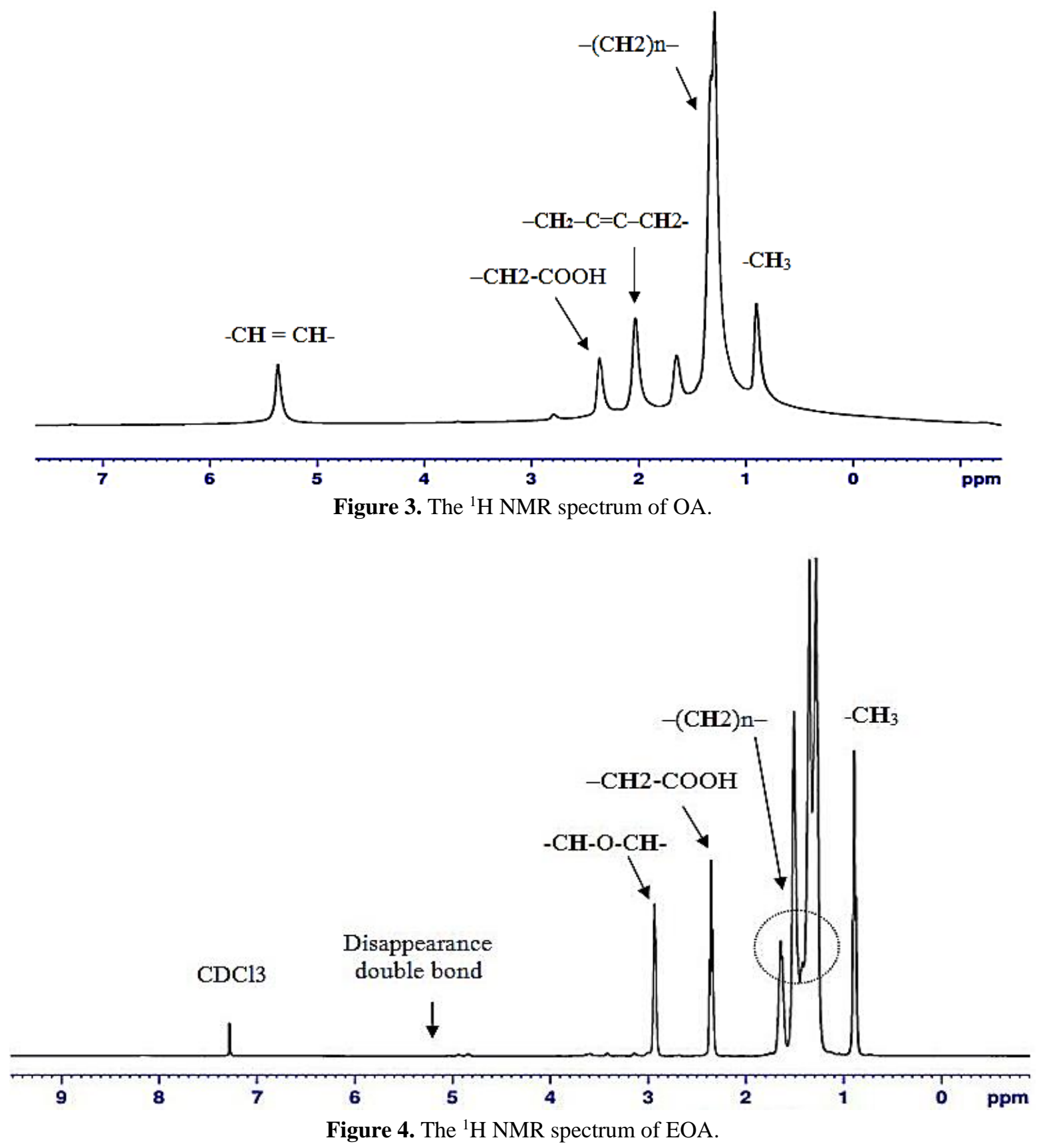

${ }^{13} \mathrm{C}$ NMR spectrum of OA and EOA are shown in Figures 5 and 6, respectively. The signal at $14.15 \mathrm{ppm}$ indicates the carbon atom of the terminal methyl group $\left(-\mathrm{CH}_{3}\right)$ in $\mathrm{OA}$, which also appears in EOA at 14.13 ppm. The carbon atoms of the terminal methyl group (- 
$\mathrm{CH}_{2}$ ) were identified by peaks at $22.6-34.07 \mathrm{ppm}$ for OA and 22.68-34.03 ppm of EOA, common for these kinds of compounds [11]. However, the signal at $180.20 \mathrm{ppm}$ denotes the carbonyl group's carbon atom $(\mathrm{C}=\mathrm{O})$ (carboxylic acid) of $\mathrm{OA}$, which also appears in the spectrum of EOA at $179.74-179.91 \mathrm{ppm}$. The other distinctive signal was at $129.75-130.24$ $\mathrm{ppm}$, which refers to the unsaturated carbon atoms $(\mathrm{C}=\mathrm{C})$ (olefinic carbon) in OA. On the other hand, the signal at $54.30-57.40 \mathrm{ppm}$ confirms the oxirane ring of EOA, indicating that the OA was converted to an EOA [23]. The signals at $76.72-77.36 \mathrm{ppm}$ attribute to $\mathrm{CDCl}_{3}$ solvent.

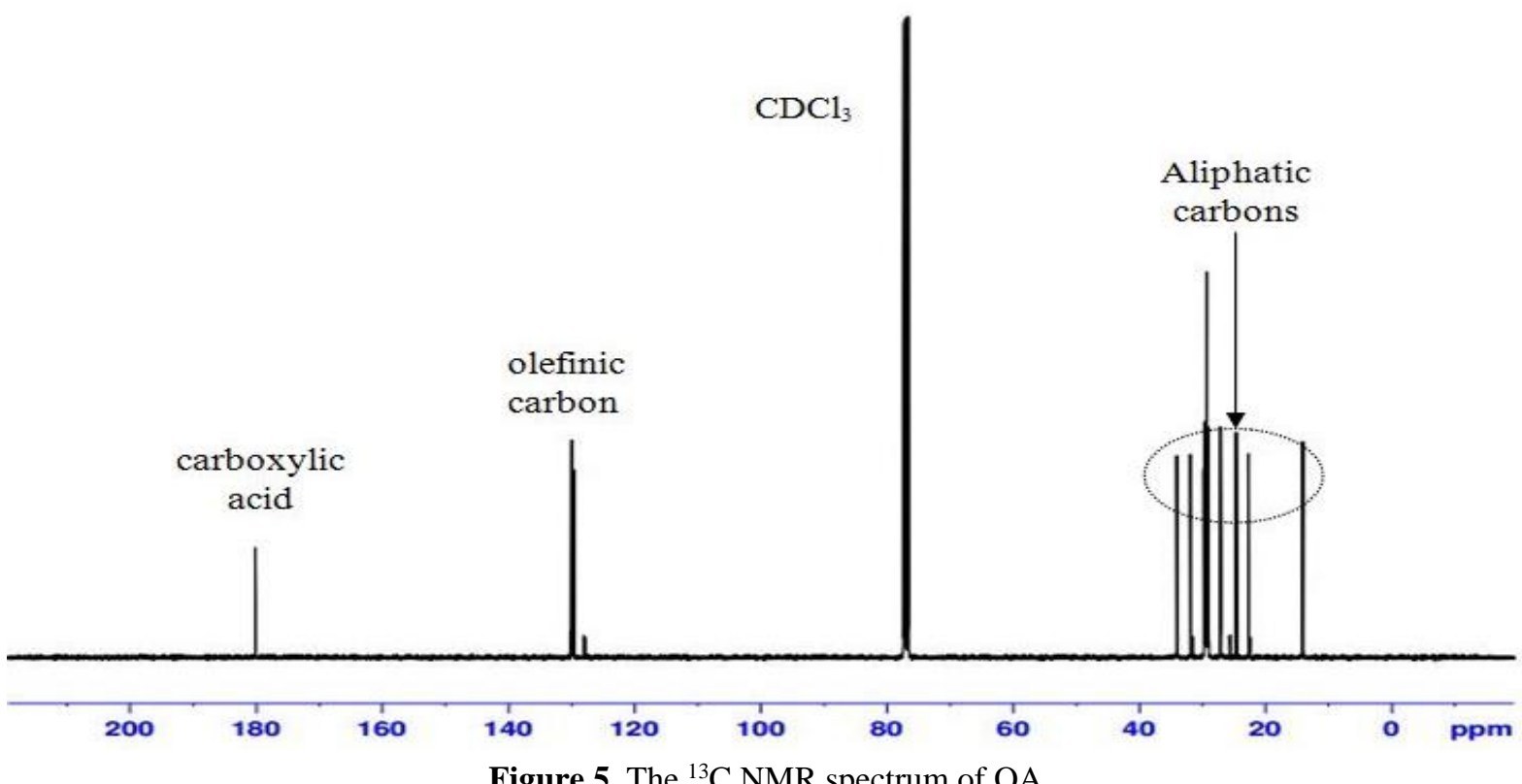

Figure 5. The ${ }^{13} \mathrm{C}$ NMR spectrum of $\mathrm{OA}$

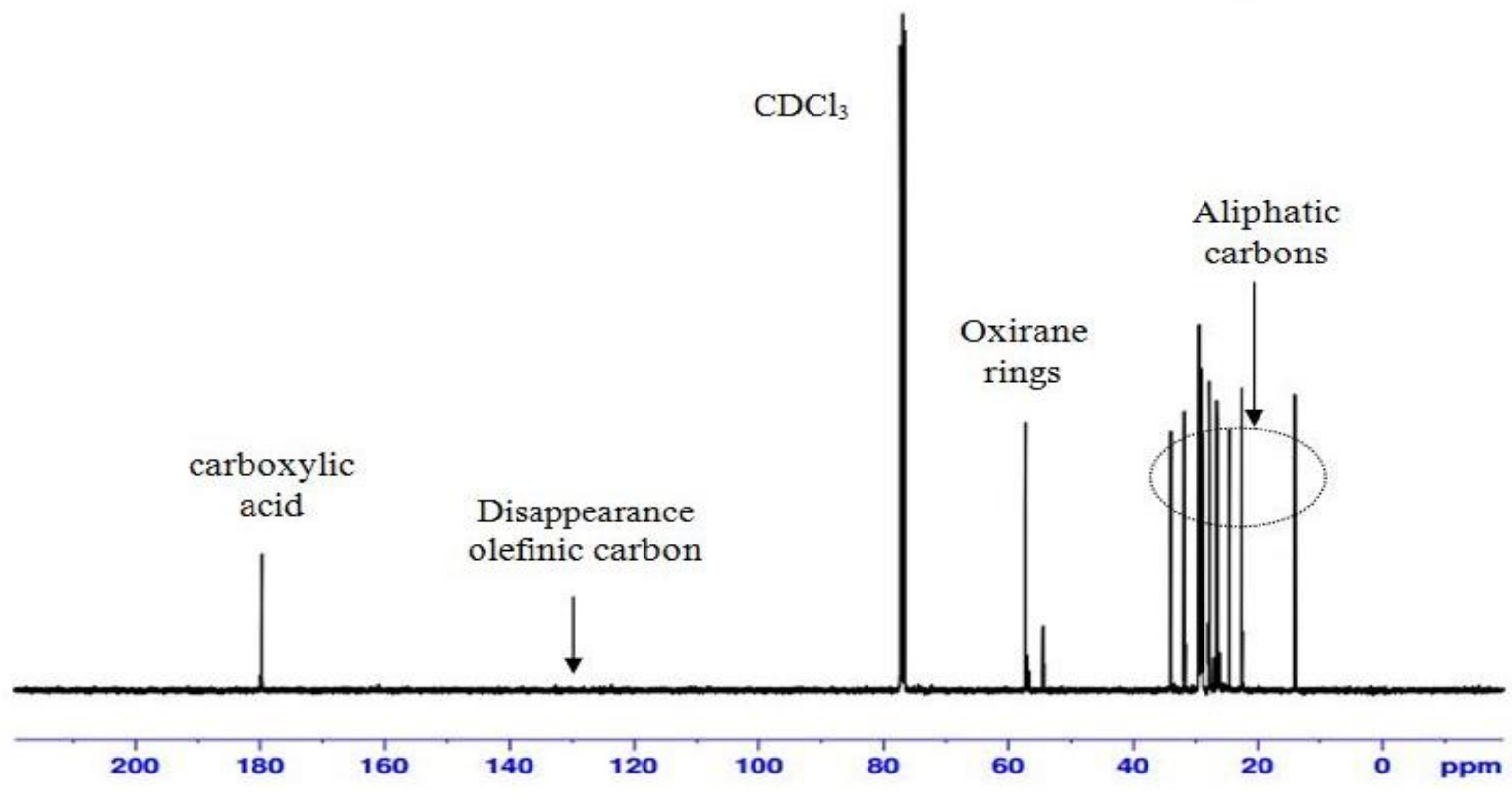

Figure 6. The ${ }^{13} \mathrm{C}$ NMR spectrum of EOA.

\subsection{Synthesis of POABP.}

This study synthesized POABP from the palm OA by heating the EOA monomer at $120^{\circ} \mathrm{C}$. The optimum reaction time was assessed by performing the synthesis in $6,12,18,24$, or $30 \mathrm{~h}$ with a magnetic stirring rate of $300 \mathrm{rpm}$. The synthesis process involves the reaction between the carboxyl and epoxy functional groups of the monomer. Figure 7 shows the chemical formation pathway of POABP from epoxidized oleic acid. A minimum of $97 \%$ yield 
of synthesized POABP was achieved, as clearly shown in Table 2. In general, it appears that polymerization for $6 \mathrm{hr}$ and $12 \mathrm{hr}$ produced a viscous liquid of POABP, while longer polymerization duration produced an extremely solid POABP. In all five polymerization times selected in this study, it can be deduced that POABP only solidifies when the polymerization is performed for 18, 24, and $30 \mathrm{hr}$, as shown in Figure 8.

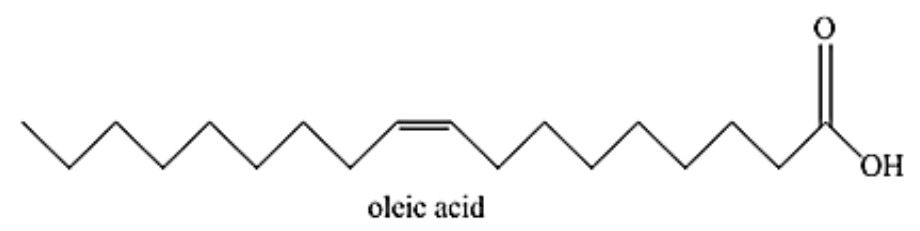

60 to $80^{\circ} \mathrm{C}$
$2 \mathrm{hr}$

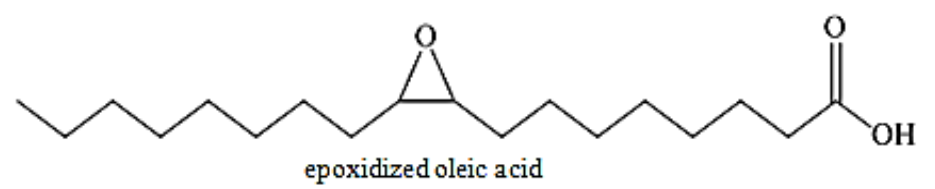

$\mid \begin{gathered}\text { Polymerization } \\ \text { at } 120^{\circ} \mathrm{C} \\ (6-30 \mathrm{hr})\end{gathered}$

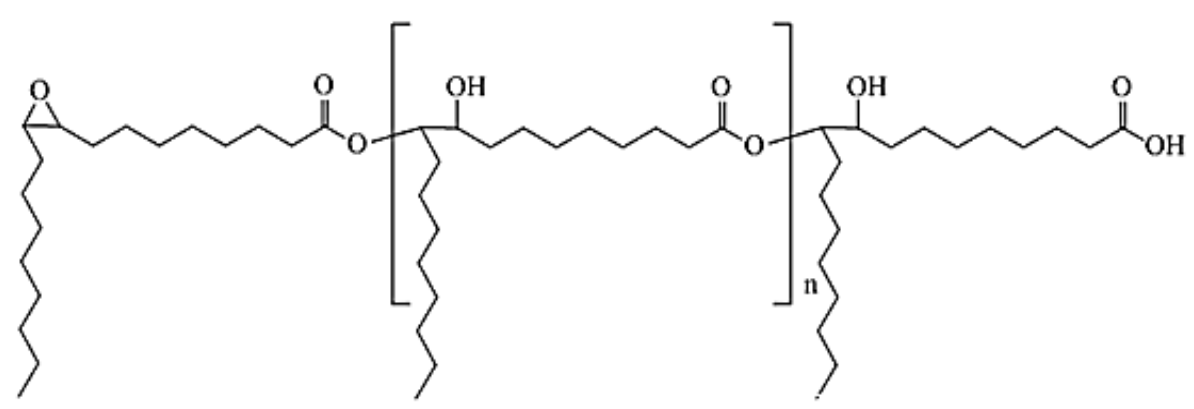

Polyester

Figure 7. The synthesis pathway of POABP.
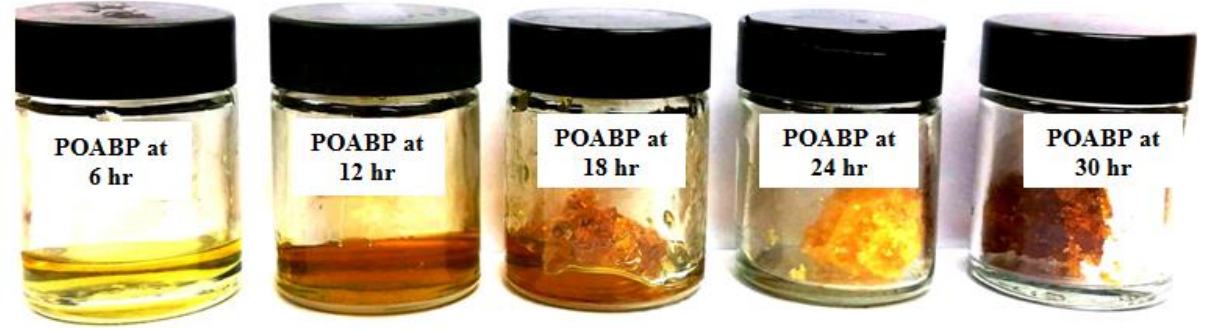

Figure 8. Palm oleic acid-based polyester (POABP).

\subsection{Characterization analysis of POABP.}

The data from NMR analysis $\left({ }^{1} \mathrm{H},{ }^{13} \mathrm{C}\right)$ and FTIR spectroscopy offers insights into the chemical structure of the synthesized POABP. The thermal strength of POABP from palm OA was evaluated using differential scanning calorimetry (DSC). Each POABP produced from the five different polymerization times occupies a different number of average molecular weight $\left(\mathrm{M}_{\mathrm{n}}\right)$. The molecular weight and polydispersity index values determined via gel permeation chromatography (GPC) are recorded in Table 2. 


\subsubsection{Molecular weights determination.}

From the results of GPC, the polyester displayed the number average molecular weight $\left(\mathrm{M}_{\mathrm{n}}\right)$ between 1810-2684 $\mathrm{g} / \mathrm{mol}$ and weight average molecular weight $\left(\mathrm{M}_{\mathrm{w}}\right)$ between 1963$5501 \mathrm{~g} / \mathrm{mol}$ at $120^{\circ} \mathrm{C}$ in $24 \mathrm{hr}$ and $300 \mathrm{rpm}$ for polyester. The polyester provided a range of 69 monomeric units, with maximum units observed at 18 and $24 \mathrm{hr}$. The polydispersity $\left(\mathrm{M}_{\mathrm{w}} / \mathrm{M}_{\mathrm{n}}\right)$ of the polyester ranged between 1.1 and 2.1. Table 2 shows the calculation of the number of monomeric units for polyester. The calculation number of monomeric units $\left(\mathrm{M}_{\mathrm{n}} / \mathrm{M}_{0}\right)$ was done by dividing the number average molecular weight $\left(\mathrm{M}_{\mathrm{n}}\right)$ by the molecular weight of the monomer unit $\left(\mathrm{M}_{0}\right)$. The mass of the polyester monomer $\left(\mathrm{EOA} \mathrm{C}_{18} \mathrm{H}_{34} \mathrm{O}_{3}\right)$ is first calculated: $(18$ carbon atoms $\times 12 \mathrm{~g} / \mathrm{mol})+(34$ hydrogen atoms $\times 1 \mathrm{~g} / \mathrm{mol})+(3$ oxygen atoms $\times 16 \mathrm{~g} / \mathrm{mol})$ $=298 \mathrm{~g} / \mathrm{mol}$ and the values of number-average molecular weight $\left(\mathrm{M}_{\mathrm{n}}\right)$ for polyester from GPC are shown in Table 2.

Based on the data presented in Table 2, it can be inferred that the formation of a high number of average molecular weight polyester is related to polymerization duration. Given the same reaction temperature of $120^{\circ} \mathrm{C}$, POABP required at least $18 \mathrm{hr}$ to solidify. The highest polymerization time $(18 \mathrm{hr}$ ) resulted in the highest number average molecular weight POABP $(2684 \mathrm{~g} / \mathrm{mol})$ with a polydispersity index of 1.4 . However, the solid polyester was insoluble in common organic solvents such as THF and chloroform because each oleic acid epoxide molecule contains only one carboxylic acid group, although an oligomer chain of the epoxide has several existing hydroxyl side groups for the formation of branched polymers. Thus, the solidified product could be a mixture of linear and branched high molecular weight polyester.

Table 2. Characterization properties of POABP.

\begin{tabular}{|c|c|c|c|c|c|c|c|c|c|c|c|}
\hline \multirow[t]{2}{*}{ Polyester } & \multicolumn{3}{|c|}{ Polymerization conditions } & \multicolumn{2}{|c|}{\begin{tabular}{|l} 
Thermal \\
properties
\end{tabular}} & \multicolumn{3}{|c|}{$\mathbf{M}_{\mathbf{w}}(\mathrm{g} / \mathbf{m o l})$} & \multirow[t]{2}{*}{$\begin{array}{l}\text { NMUs } \\
\left(\mathrm{M}_{\mathrm{n}} / \mathrm{M}_{0}\right)\end{array}$} & \multirow[t]{2}{*}{ PDI } & \multirow[t]{2}{*}{$\begin{array}{l}\text { Yield } \\
(\%)\end{array}$} \\
\hline & \begin{tabular}{|l|}
$\begin{array}{l}\text { Time } \\
\text { (hr) }\end{array}$ \\
\end{tabular} & $\begin{array}{l}\text { Temp. } \\
(\mathrm{C})\end{array}$ & \begin{tabular}{|l|}
$\begin{array}{l}\text { Stirring } \\
(\mathbf{r p m})\end{array}$ \\
\end{tabular} & $\begin{array}{l}\mathbf{T}_{\mathbf{g}} \\
\left({ }^{\circ} \mathbf{C}\right) \\
\end{array}$ & $\mathbf{T}_{\mathrm{d}}\left({ }^{\circ} \mathbf{C}\right)$ & $M_{n}$ & $\mathbf{M}_{\mathbf{w}}$ & $\mathbf{M}_{\mathbf{0}}$ & & & \\
\hline POABP 1 & 6 & 120 & 300 & -21.44 & 328.5 & 1810 & 1963 & 298 & 6 & 1.1 & 98.46 \\
\hline POABP 2 & 12 & 120 & 300 & $\begin{array}{l}- \\
20.09\end{array}$ & 334.6 & 2309 & 2682 & 298 & 8 & 1.2 & 98.30 \\
\hline POABP 3 & 18 & 120 & 300 & \begin{tabular}{|l|}
- \\
20.14 \\
\end{tabular} & 336.6 & 2684 & 3637 & 298 & 9 & 1.4 & 97.95 \\
\hline POABP 4 & 24 & 120 & 300 & - & 342.3 & 2591 & 5501 & 298 & 9 & 2.1 & 97.86 \\
\hline POABP 5 & 30 & 120 & 300 & - & - & - & - & 298 & - & - & 97.80 \\
\hline
\end{tabular}

Notes: $T_{g}=$ Glass transition temp; $T_{d}=$ Decomposition temp; $M_{n}=$ Number average molecular weight; $M_{w}=$ Weight average molecular weight; $\mathrm{M}_{0}=$ Molecular weight of the monomer unit of (EOA); NMUs = Number of monomeric units for polyester; PDI = Polydispersity index $\left(M_{w} / M_{n}\right)$

\subsubsection{Thermal properties analysis.}

The palm oleic acid-based polyester's thermal behavior was evaluated in the range of 50 to $500^{\circ} \mathrm{C}$ using DSC to take advantage of the possible emergence of transition peaks indicative of melting, crystallization, glass transition, and polymer degradation simultaneously. No prominent melting point was observed in the DSC analysis (Figure 9). The glass transition temperature $\left(\mathrm{T}_{\mathrm{g}}\right)$ value of all samples was detected in the range of -19 to $-20^{\circ} \mathrm{C}$. Thermal stability is important for evaluating the chemical recycling potential of a polymer. The thermal decomposition of POABP started between 328 and $343^{\circ} \mathrm{C}$, denoted as the polymers' degradation peak range or the onset temperature, thereby terming decomposition temperature $\left(\mathrm{T}_{\mathrm{d}}\right)$. 


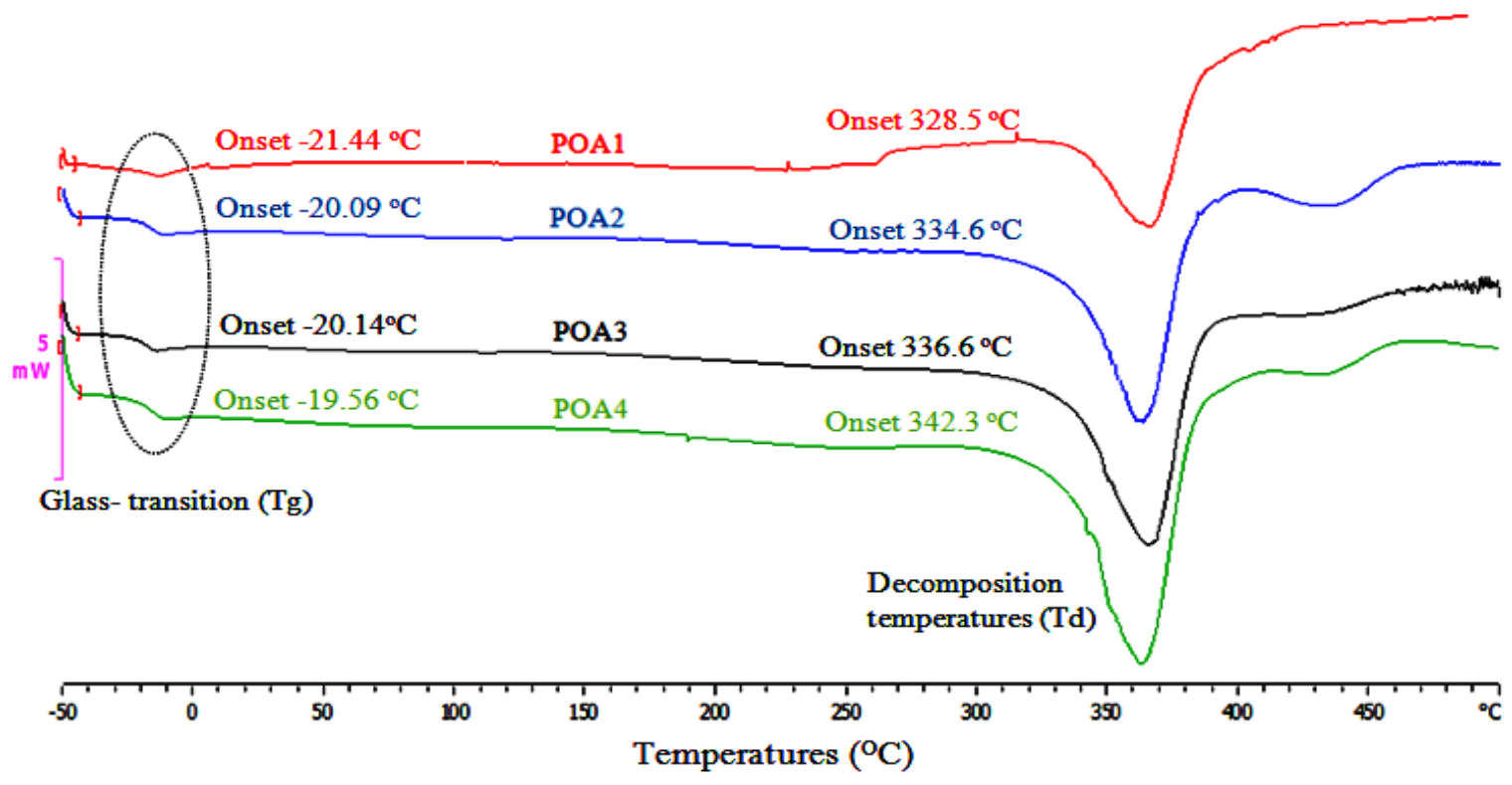

Figure 9. The DSC thermogram of POABP.

\subsubsection{FTIR analysis.}

The highly predicted outcome of this study is the formation of the ester group in the POABP, the presence of ester was validated using FTIR analysis. According to Pavia et al. (2010) [24], characteristic peak of stretching vibration of the carbonyl group for aliphatic esters may be present in the range of $1732-1736 \mathrm{~cm}^{-1}$, while the $\mathrm{C}-\mathrm{O}$ esters are denoted by the characteristic peak of stretching vibration of carboxylic acids in the range of $1690-1725 \mathrm{~cm}^{-1}$. The functional groups and their positions for all the POABP synthesized at 6, 12, 18, and 24 $\mathrm{hr}$ were extracted from the FTIR spectra and compiled in Figure 10. It is rather interesting to detect a carboxyl group's peak $(\mathrm{C}=\mathrm{O})$ at $1700 \mathrm{~cm}-1$, associated with an oleic acid epoxide, apparently decreased after polymerization. Meanwhile, the new peaks observed at 1734 and $3450 \mathrm{~cm}^{-1}$ suggest the ester group's formation (-COOR) and hydroxyl group (-OH), respectively. The carboxyl group peaks at 1713 and $1718 \mathrm{~cm}^{-1}$ appeared to be larger for polymers synthesized for 6 and $12 \mathrm{hr}$ than those synthesized for 18 and $24 \mathrm{hr}$, indicating higher conversion yields at longer synthesis duration, given the constant polymerization temperature $\left(120^{\circ} \mathrm{C}\right)$ for each set. The bands observed at 1245 and $1173 \mathrm{~cm}^{-1}$ in all synthesized POABP indicate $\mathrm{C}-\mathrm{O}$ ester linkages.

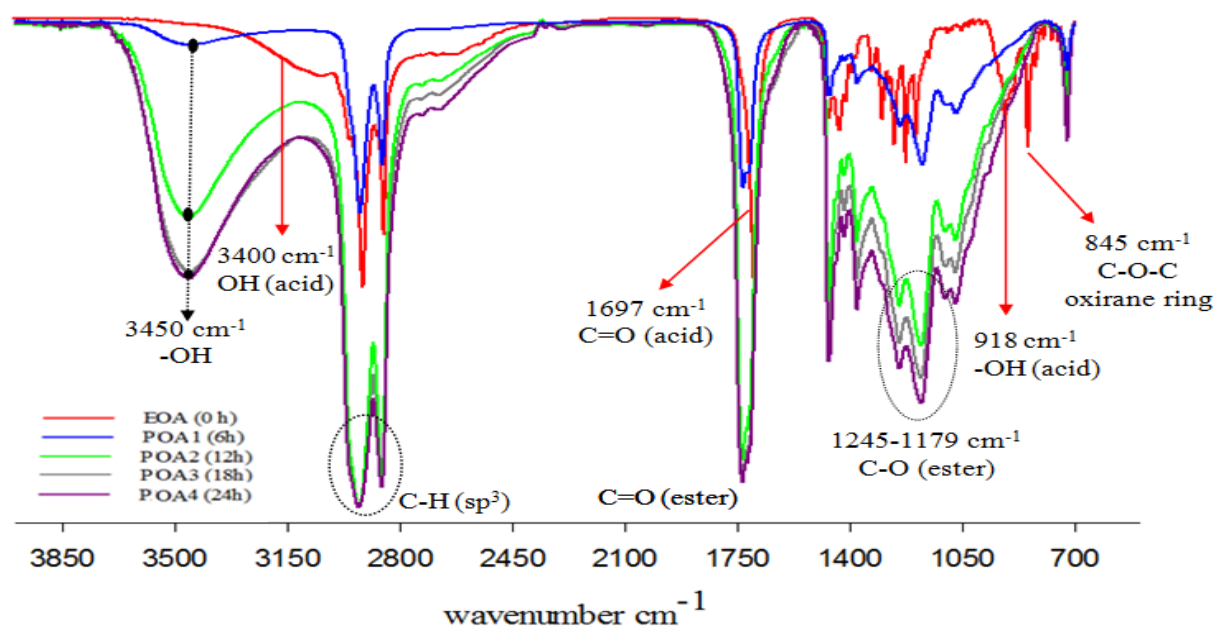

Figure 10. The FTIR spectrum of POABP. 


\subsubsection{NMR analysis.}

${ }^{1} \mathrm{H}$ and ${ }^{13} \mathrm{C}$ NMR analysis are possibly the most valuable techniques for analyzing the chemical structure. FT- NMR NMR400 MHz was used to determine the molecular chemical structure of POABP. The FT- NMR spectrum is exhibited in Figure 11. As anticipated, the epoxide group (proton signal is shown at $2.9 \mathrm{ppm}$ ) disappeared after polymerization. The chemical shift at $4.8 \mathrm{ppm}$ indicates the presence of ester group $\mathrm{RCOO}-\mathrm{CH}_{2}$ (i). The chemical shifts at 2.34, 3.4, and $3.6 \mathrm{ppm}$ are assigned to -aliphatic $-\mathrm{CH}_{2}-\mathrm{COOR}(\mathrm{f}), \mathrm{HO}-\mathrm{CH}-$ branch $(\mathrm{g})$, and $\mathrm{H}-\mathrm{C}-\mathrm{OH}(\mathrm{h})$, respectively. The $-\mathrm{CH}_{2}-(\mathrm{d} \& \mathrm{e})$ chemical shift was detected at 1.53 and 1.62 ppm, while the signal at $0.87 \mathrm{ppm}$ is assigned to the methyl group (- $\left.\mathrm{CH}_{3}(\mathrm{a})\right)$. Finally, the chemical shift at $1.25-1.30 \mathrm{ppm}$ is assigned to terminal methyl $-\mathrm{CH}_{2}-(\mathrm{b})$.

As shown in Figure 12, the ${ }^{13} \mathrm{C}$ NMR chemical shifts at $173.79 \mathrm{ppm}$ and $72.5 \mathrm{ppm}$ indicate the presence of $(\mathrm{C}=\mathrm{O})$ (ester group in poly oleic acid structure) and $\mathrm{C}$ atom adjacent to oxygen $\left(\mathrm{O}-\mathrm{CH}_{2}\right)(\mathrm{i})$, respectively. The signals at 34.48 and $33.86 \mathrm{ppm}$ indicate the presence of $\mathrm{C}$ atom adjacent to carbonyl $\left(\mathrm{CH}_{2} \mathrm{C}=\mathrm{O}\right)(\mathrm{f})$, and $24.7 \mathrm{ppm}$ for $-\mathrm{CH}_{2}-(\mathrm{d})$. The chemical shifts at $31.88,31.86,30.59,29.72,29.53,29.09,25.08$, and $22.68 \mathrm{ppm}$ are assigned to $-\mathrm{CH}_{2}-$ (b), while that of 14.14 ppm denotes terminal methyl $-\mathrm{CH}_{3}$.

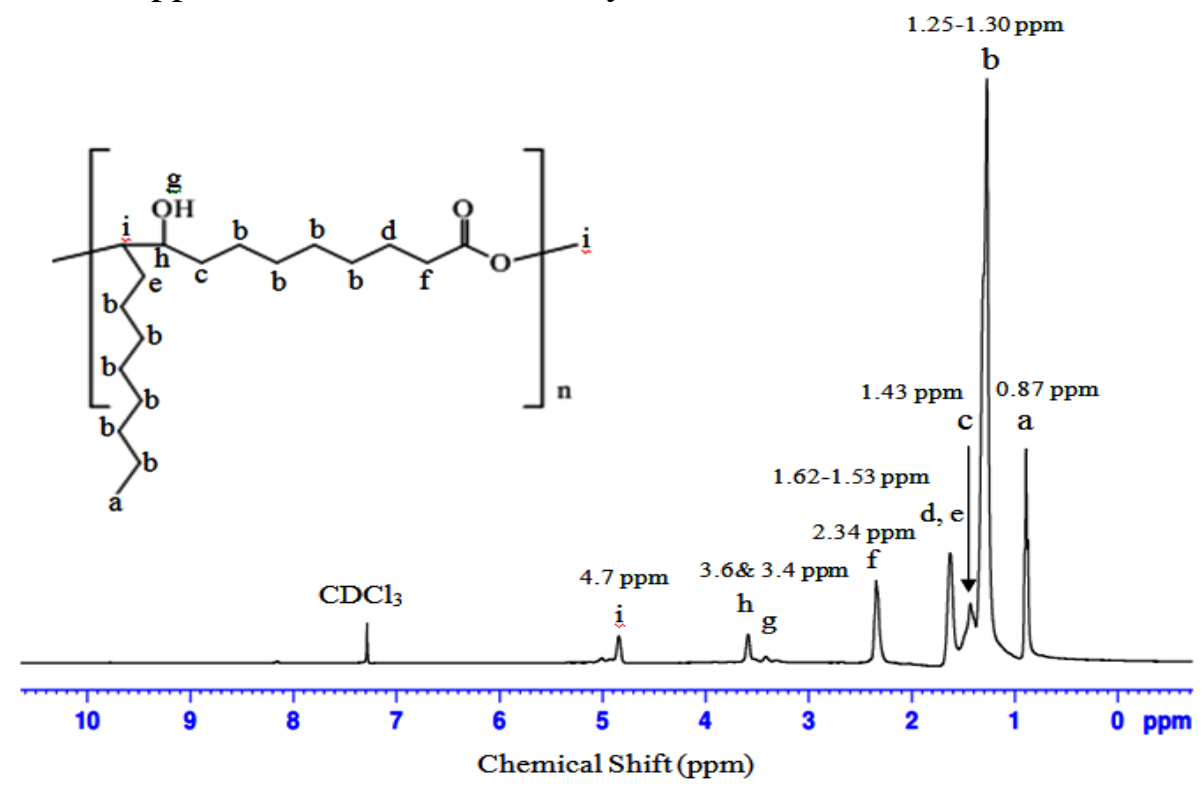

Figure 11. The ${ }^{1} \mathrm{H}$ NMR spectrum of POABP.

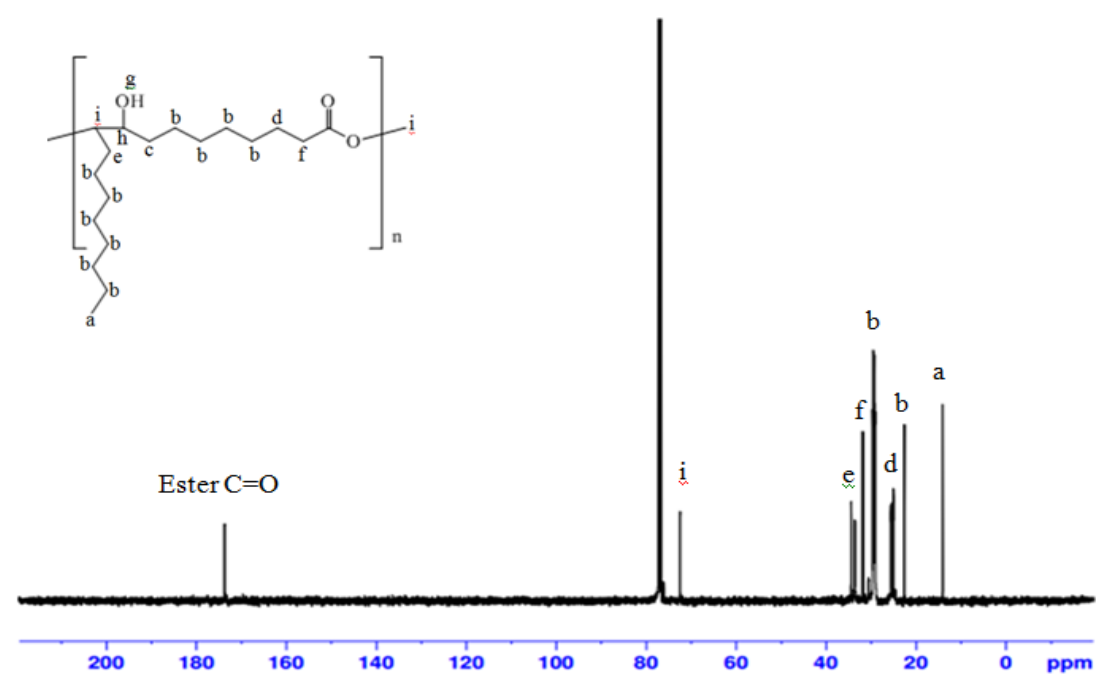

Figure 12. The ${ }^{13} \mathrm{C}$ NMR spectrum of POABP. 


\section{Conclusions}

Many researchers have researched epoxidized plant oils in the past years because of their renewable and sustainable resource characteristics suitable and plausible for replacing petrochemical raw material in the future. This study involves the successful preparation of EOA from OA originating from $\mathrm{CPO}$, which was subsequently heated at $120^{\circ} \mathrm{C}$ to synthesize a polyester polymer. The chemical structure and formation of internal ester groups of the polyester were determined by ${ }^{1} \mathrm{H},{ }^{13} \mathrm{C}$ NMR, and FTIR analysis. The polyester polymer oleic acid products exhibited glass transition temperature at $-19^{\circ} \mathrm{C}$ and thermal degradation after $328^{\circ} \mathrm{C}$. The POABP can be used as a precursor to the plastic industry.

\section{Funding}

This research was funded by grant no. FRGS/2/2014/ST01/UKM/02/1 and Sime Darby grant no. ST-2014-019.

\section{Acknowledgments}

The authors acknowledge the support staff's direct contributions from the Department of Chemical Sciences, Faculty of Science and Technology, Universiti Kebangsaan Malaysia, and Ministry of Science, Technology, and Innovation (MOSTI).

\section{Conflicts of Interest}

The authors declare no conflict of interest.

\section{References}

1. Chen, J.; de Liedekerke Beaufort, M.; Gyurik, L.; Dorresteijn, J.; Otte, M.; Klein Gebbink, R.J.M. Highly efficient epoxidation of vegetable oils catalyzed by a manganese complex with hydrogen peroxide and acetic acid. Green Chem. 2019, 21, 2436-2447, https://doi.org/10.1039/c8gc03857k.

2. Bahadi, M.; Yusoff, M.F.; Salimon, J.; Derawi, D. Optimization of response surface methodology by Doptimal design for synthesis of food-grade palm kernel based biolubricant. Industrial Crops and Products 2019, 139, 111452, https://doi.org/10.1016/j.indcrop.2019.06.015.

3. Lye, Y.N.; Salih, N.; Salimon, J. Optimization of partial epoxidation on Jatropha curcas oil based methyl linoleate using urea-hydrogen peroxide and methyltrioxorhenium catalyst. Appl Sci Eng Prog 2021, 14, 8999, https://doi.org/10.14416/j.asep.2020.12.006.

4. Salimon, J.; Abdullah, B.M.; Salih, N. Selectively increasing of polyunsaturated (18:2) and monounsaturated (18:1) fatty acids in Jatropha curcas seed oil by crystallization using D-optimal design. Chem. Cent. J. 2012, 6, 65, https://doi.org/10.1186/1752-153x-6-65.

5. Afifah, A.N.; Syahrullail, S.; Wan Azlee, N.I.; Che Sidik, N.A.; Yahya, W.J.; Abd Rahim, E. Biolubricant production from palm stearin through enzymatic transesterification method. Biochem. Eng. J. 2019, 148, 178184, https://doi.org/10.1016/j.bej.2019.05.009.

6. dos Santos, L.K.; Hatanaka, R.R.; de Oliveira, J.E.; Flumignan, D.L. Production of biodiesel from crude palm oil by a sequential hydrolysis/esterification process using subcritical water. Renewable Energy 2019, 130, 633-640, https://doi.org/10.1016/j.renene.2018.06.102.

7. Bakare, I.O.; Pavithran, C.; Okieimen, F.E.; Pillai, C.K.S. Polyesters from renewable resources: Preparation and characterization. J. Appl. Polym. Sci. 2006, 100, 3748-3755, https://doi.org/10.1002/app.23386.

8. Seniha Güner, F.; Yağcı, Y.; Tuncer Erciyes, A. Polymers from triglyceride oils. Prog. Polym. Sci. 2006, 31, 633-670, https://doi.org/10.1016/j.progpolymsci.2006.07.001.

9. Derawi, D.; Fadzel, F.M.; Salimon, J. Biolubricant production from palm stearin fatty acids and pentaerythritol. Malaysian J Chem 2019, 21, 50-63. 
10. Sherazi, S.T.H.; Kandhro, A.; Mahesar, S.A.; Bhanger, M.I.; Talpur, M.Y.; Arain, S. Application of transmission FT-IR spectroscopy for the trans fat determination in the industrially processed edible oils. Food Chem. 2009, 114, 323-327, https://doi.org/10.1016/j.foodchem.2008.09.058.

11. Bahadi, M.A.; Yusoff, M.F.; Salimon, J., Japir, A.A.W.; Derawi, D. Optimization of low-temperature methanol crystallization for unsaturated fatty acids separation from crude palm fatty acids mixture using response surface methodology. Asian $J$ Chem 2019, 31, 1617-1625, https://doi.org/10.14233/ajchem.2019.21974.

12. Djomdi; Leku, M.T.; Djoulde, D.; Delattre, C.; Michaud, P. Purification and Valorization of Waste Cotton Seed Oil as an Alternative Feedstock for Biodiesel Production. Bioengineering 2020, 7 , https://doi.org/10.3390/bioengineering7020041.

13. AOCS, Official Methods and Recommended Practices of the American Oil Chemists' Society, $4^{\text {th }}$ Ed., Champaign Illinois, USA, 1989.

14. Corrêa, F.d.A.; Sutili, F.K.; Miranda, L.S.M.; Leite, S.G.F.; De Souza, R.O.M.A.; Leal, I.C.R. Epoxidation of oleic acid catalyzed by PSCI-Amano lipase optimized by experimental design. J. Mol. Catal. B: Enzym. 2012, 81, 7-11, https://doi.org/10.1016/j.molcatb.2012.03.011.

15. Bahadi, M.; Yusoff, M.F.; Derawi, J.S.; Darfizzi. Optimization of response surface methodology by d-optimal design for alkaline hydrolysis of crude palm kernel oil. Sains Malays 2020, 49, 29-41, https://doi.org/10.17576/jsm-2020-4901-04.

16. Kushairi, A.; Ong-Abdullah, M.; Nambiappan, B.; Hishamuddin, E.; Bidin, M.; Ghazali, R.; Subramaniam, V.; Sundram, S.; Parveez, G.K.A. Oil palm economic performance in Malaysia and R\&D progress in 2018. J. Oil Palm Res 2019, 31, 165-194, https://doi.org/10.21894/jopr.2019.0026.

17. Liu, C.; Meng, Z.; Chai, X.; Liang, X.; Piatko, M.; Campbell, S.; Liu, Y. Comparative analysis of graded blends of palm kernel oil, palm kernel stearin and palm stearin. Food Chem. 2019, 286, 636-643, https://doi.org/10.1016/j.foodchem.2019.02.067.

18. Moreira, D.R.; Chaves, P.O.B.; Ferreira, E.N.; Arruda, T.B.M.G.; Rodrigues, F.E.A.; Neto, J.F.C.; Petzhold, C.L.; Maier, M.E.; Ricardo, N.M.P.S. Moringa polyesters as eco-friendly lubricants and its blends with naphthalenic lubricant. Industrial Crops and Products 2020, 158, 112937 , https://doi.org/10.1016/j.indcrop.2020.112937.

19. Kozhevnikov, I.V.; Mulder, G.P.; Steverink-de Zoete, M.C.; Oostwal, M.G. Epoxidation of oleic acid catalyzed by peroxo phosphotungstate in a two-phase system. J. Mol. Catal. A: Chem. 1998, 134, 223-228, https://doi.org/10.1016/s1381-1169(98)00039-9.

20. Mudhaffar, B.; Salimon, J. Epoxidation of vegetable oils and fatty acids: catalysts, methods and advantages. Journal of Applied Sciences 2010, 10, 1545-1553, https://doi.org/10.3923/jas.2010.1545.1553.

21. Nor, N.M.; Derawi, D.; Salimon, J. Esterification and evaluation of palm oil as biolubricant base stock. Malaysian J Chem 2019, 21, 28-35.

22. Nor, N.M., Salih, N.; Salimon, J. Optimization of the ring opening of epoxidized palm oil using D-optimal design. Asian J Chem 2021, 33, 67-75, https://doi.org/10.14233/ajchem.2021.22938.

23. Sagan, A.; Blicharz-Kania, A.; Szmigielski, M.; Andrejko, D.; Sobczak, P.; Zawiślak, K.; Starek, A. Assessment of the Properties of Rapeseed Oil Enriched with Oils Characterized by High Content of $\alpha$ linolenic Acid. Sustainability 2019, 11, https://doi.org/10.3390/su11205638.

24. Pavia, D.L., Lampman, G.M.; Kriz, G.S. Introduction to Spectroscopy, $4^{\text {th }}$ ed., USA Thomson learning, 2010. 